\title{
LA ORDEN EUROPEA DE RETENCIÓN DE CUENTAS: UNA APUESTA DECIDIDA PARA LA TUTELA CAUTELAR DEL CRÉDITO EN ASUNTOS TRANSFRONTERIZOS
}

\author{
Carmen SenÉs Motilla*
}

SUMARIO: 1. INTRODUCCIÓN.-2. NATURALEZA JURÍDICA DE LA ORDEN: MEDIDA CAUTELAR UNIFORME, OPCIONAL Y AUTÓNOMA RESPECTO DEL EMBARGO.-3. ÁMBITO DE APLICACIÓN DE LA ORDEN: «ASUNTOS TRANSFRONTERIZOS» Y EXCLUSIÓN DE LOS INSTRUMENTOS FINANCIEROS.-4. FACTORES CLAVES DE LA EFICACIA DE LA ORDEN: ADOPCIÓN INAUDITA PARTE DEBITORIS Y PETICIÓN DE INFORMACIÓN SOBRE LAS CUENTAS DEL DEUDOR.-5. EJECUCIÓN Y CUMPLIMENTACIÓN DE LA ORDEN: SUPRESIÓN DEL EXEQUÁTUR Y PRÁCTICA DE LA RETENCIÓN.-6. RETENCIÓN DE CUENTAS CONJUNTAS Y NOMINALES: REENVÍO AL DERECHO DEL ESTADO MIEMBRO DE EJECUCIÓN.-7. VALORACIÓN FINAL.

\section{INTRODUCCIÓN}

1. La tutela procesal del crédito en un entorno transfronterizo ha sido una constante de la Unión Europea en las dos últimas décadas, cuyos hitos más destacados son instrumentos procesales de nuevo cuño, como el sistema de reconocimiento y ejecución del título ejecutivo europeo y los procedimientos europeos armonizados (PME y PEEC). La aportación a este foro tiene por objeto el instrumento de más reciente creación, la Orden Europea de Retención de Cuentas (OERC o la orden), que vio la luz mediante el Reglamento núm. 655/2014 ${ }^{1}$. Esta reglamentación no deja indiferente al jurista, siquiera sea porque la generalidad de los mortales dispone de cuentas bancarias y tiene cabal representación del calado que comporta la retención.

2. La selección temática que acometemos persigue tres objetivos: tomar posicionamiento frente a cuestiones controvertidas de la orden; resaltar

\footnotetext{
* Estudio realizado en el marco del Proyecto «Tratamiento procesal de las cláusulas abusivas y de los instrumentos financieros complejos» (DER2014-51957-P), Ministerio de Economía y Competitividad. Carmen Senés Motilla es Catedrática de Derecho Procesal en la Universidad de Almería (csenes@ual.es).

1 Reglamento (UE) núm. 655/2014, del Parlamento Europeo y del Consejo, de 15 de mayo, por el que se establece el procedimiento relativo a la orden europea de retención de cuentas a fin de simplificar el cobro transfronterizo de deudas en materia civil y mercantil, DO L núm. 189, de 27 de junio de 2014.
} 
las diferencias que la separan de la medida equivalente en Derecho español -el embargo preventivo-, y dar cuenta de la conveniencia de reformar la Ley 1/2000, de 7 de enero, de Enjuiciamiento Civil ${ }^{2}$ (en adelante, LEC), tanto para implementar la aplicación de la orden como para asimilar a su régimen jurídico determinados aspectos del embargo de cuentas ${ }^{3}$.

\section{NATURALEZA JURÍDICA DE LA ORDEN: MEDIDA CAUTELAR UNIFORME, OPCIONAL Y AUTÓNOMA RESPECTO DEL EMBARGO}

3. Frente a los procedimientos europeos armonizados la OERC es una medida cautelar, y como tal, es instrumental respecto de los procedimientos de reclamación de deudas que se siguen en los Estados miembros, aunque con la singularidad notable de que también puede ser solicitada por el acreedor que ha visto reconocido su crédito en resolución judicial, transacción judicial o documento público con fuerza ejecutiva. La razón de esta disfunción "aparente» son las implicaciones de la reclamación de deudas en un entorno transfronterizo, que mediatizan el interés del acreedor en la incoación del proceso de ejecución; por ejemplo, en espera de que sea confirmada la sentencia favorable que ha sido impugnada por el deudor condenado al pago.

4. El Reglamento establece una medida cautelar que permite al acreedor obtener la retención de las cuentas del deudor, conjurando así el riesgo de que pueda disponer de los fondos que mantiene en cuentas abiertas en el territorio de la Unión o que los transfiera a una cuenta que cae fuera del control de los órganos jurisdiccionales de los Estados miembros. Este riesgo se ha visto incrementado exponencialmente con los servicios de la banca electróni$\mathrm{ca}$, que permiten movilizar los fondos desde y hacia cualquier lugar del mundo en cuestión de segundos. Y a tamaño riesgo, tamaña solución: la OERC se adopta, se ejecuta y se cumplimenta, inaudita parte debitoris, y es eficaz en el Estado en que el deudor mantiene la cuenta sin necesidad de reconocimiento ni declaración de ejecutividad.

5. La OERC es una medida uniforme y opcional (art. 1.2). En tanto que uniforme, el Reglamento es directamente aplicable en los Estados miembros vinculados por él, sin perjuicio de la diversificación de su aplicación debido a las numerosas remisiones al Derecho nacional. Por su parte, el carácter opcional engloba dos realidades: el genuino carácter alternativo de la orden respecto de las medidas previstas en el Derecho de los Estados miembros y su eventual carácter complementario respecto de una «orden nacional equi-

\footnotetext{
BOE núm. 7, de 8 de enero de 2000.

3 Un estudio monográfico de la OERC puede verse en SEnÉs Motilla, C., La orden europea de retención de cuentas. Aplicación en Derecho Español del Reglamento (UE) núm. 655/2014, de 15 de mayo de 2014, Cizur Menor (Navarra), Thomson Reuters Aranzadi, 2015.
} 
valente» que el acreedor haya solicitado u obtenido frente al deudor y que abone la adopción de una orden de retención parcial (art. 16.4).

6. La OERC solo está a disposición de los acreedores domiciliados en un Estado miembro vinculado por el Reglamento, exigencia explícita en el concepto de «acreedor» [art. 4, punto 6)]. Es más, si los fondos existentes en la cuenta que deba retenerse fueran insuficientes para cubrir la cuantía de la orden deberá cumplimentarse en la cantidad disponible en dicha cuenta, sin posibilidad de ulterior reenvío a un tercer Estado miembro diferente del Estado miembro de ejecución (art. 24.6).

7. Desde la óptica del proceso civil español, merece destacarse la autonomía de la orden respecto del embargo preventivo, en el que la orden de retención «interna» se configura como medida de garantía de la traba (art. 621.2 LEC). Se adopta, por tanto, conforme a las normas de aquel, en particular, la que sanciona el orden de los bienes embargables (art. 592 LEC). La OERC, en cambio, opera al margen del embargo y sus requisitos se infieren del Reglamento, lo que entre otras especialidades comporta la posible exención al acreedor de la caución (art. 12).

8. A nuestro parecer, la OERC difícilmente puede merecer rechazo. Es cierto que buena parte de las deficiencias que antaño padeciera el Derecho comunitario en materia cautelar se han visto paliadas por el Reglamento núm. 1215/20124. Pero la orden supone un plus a favor de la tutela del crédito en asuntos transfronterizos, pues aunque sirva para conjurar un riesgo antiguo -la insolvencia del deudor - es adecuada para combatir esa «operativa nueva» que lo ha incrementado: la transferencia de los fondos bancarios a golpe de «clic».

\section{3. ÁMBITO DE APLICACIÓN DE LA ORDEN: «ASUNTOS TRANSFRONTERIZOS»Y EXCLUSIÓN DE LOS INSTRUMENTOS FINANCIEROS}

9. El Reglamento es aplicable a las «deudas pecuniarias en materia civil y mercantil en asuntos transfronterizos que se definen en el art. 3» (art. 2.1). La configuración del "asunto transfronterizo» ha resultado controvertida. Por una parte, debido a la versión del Reglamento en español, que sugiere que las circunstancias recogidas en las letras $a$ ) y $b$ ) del art. 3.1 son acumulativas, cuando son alternativas. Y por otra parte, porque no requiere «un viaje entre jurisdicciones» de diferentes Estados miembros 5 .

10. Sobre la primera cuestión, véanse las versiones del Reglamento en inglés, francés e italiano, que prevén como alternativas las circunstancias ci-

\footnotetext{
${ }^{4}$ Reglamento (UE) núm. 1215/2012, del Parlamento Europeo y del Consejo, de 12 de diciembre, relativo a la competencia judicial, el reconocimiento y la ejecución de resoluciones judiciales en materia civil y mercantil (refundición), DO L núm. 351, de 20 de diciembre de 2012.

5 Vilas Álvarez, D., «El Reglamento por el que se crea una Orden Europea de Retención de Cuentas: claves de su elaboración», La Ley Mercantil, 2014, núm. 6 (septiembre), p. 8.
} 
tadas, de suerte que, el carácter transfronterizo de un asunto podrá venir determinado por la concurrencia de una de ellas. Así lo avala el Preámbulo cuando aclara que el asunto es también transfronterizo si el acreedor está domiciliado en un Estado miembro y el órgano jurisdiccional y la cuenta bancaria que haya de retenerse estén situados en otro Estado miembro (considerando 10). En este supuesto, en un mismo Estado miembro concurrirá la doble condición de Estado «de origen» y «de ejecución».

11. Respecto de la segunda cuestión procede ratificar, en primer término, que la configuración del asunto transfronterizo al margen del tránsito entre jurisdicciones no es novedosa, pues los Reglamentos sobre los procesos monitorio europeo y de escasa cuantía ya permiten la sustanciación de estos en un Estado miembro que también puede ser el Estado de ejecución del requerimiento de pago declarado ejecutivo o de la sentencia (arts. 3.1 RPME y 3.1 RPEEC). Y, en segundo término, estimamos abonada esta configuración porque, a diferencia del carácter único de otros puntos de conexión -domicilio-, la orden tiene por objeto los fondos depositados en cuentas que el deudor puede abrir en cualquier Estado miembro, de suerte que involucrar tal reenvío en el asunto transfronterizo supondría limitar su ámbito de aplicación.

12. Determinar qué cuentas pueden ser objeto de retención fue cuestión controvertida en la elaboración del Reglamento, no habiendo prevalecido la Propuesta de la Comisión que propugnaba su extensión a los instrumentos financieros ${ }^{6}$. La exclusión de estos -incluida la participación en fondos de inversión armonizados conforme a la Directiva 2009/65/ $\mathrm{CE}^{7}$ - determina que el ámbito de la orden sea muy restringido. Esta restricción no es plenamente satisfactoria, aunque pudiera considerarse prudente atendida la mayor complejidad que puede comportar la determinación de la titularidad de estos fondos, así como que la Comisión «no haya tirado la toalla» sobre el particular [art. 53.1, letra $a)$ ].

\section{FACTORES CLAVES DE LA EFICACIA DE LA ORDEN: ADOPCIÓN INAUDITA PARTE DEBITORIS Y PETICIÓN DE INFORMACIÓN SOBRE LAS CUENTAS DEL DEUDOR}

13. Con origen en la Propuesta presentada por la Comisión, la adopción de la OERC tiene lugar inaudita parte (art. 11). Es este un principio nuclear del procedimiento cuya incidencia comprende, además de la provisión sobre la solicitud de orden y la ejecución de esta, la sustanciación del recurso frente a la desestimación de la solicitud (art. 21.3). La razón del principio es salvaguardar el efecto sorpresa de la orden y consiguiente eficacia de esta; y ello, hasta el punto de informar el aplazamiento de la notificación al deudor - du-

\footnotetext{
6 Art. 4, apartados 1 y 5; $\operatorname{COM(2011)~} 445$ final.

7 Vilas Álvarez, op. cit., nota 5, p. 9.
} 
rante treinta días- de que se han revelado sus datos personales si el acreedor hubiera solicitado la obtención de información sobre sus cuentas (art. 14.8 y considerando 46).

14. El principio inaudita parte constituye una excepción del régimen de tutela cautelar del Reglamento 1215/2012, que solo autoriza el reconocimiento y ejecución de las medidas cautelares adoptadas por el órgano jurisdiccional competente en cuanto al fondo si el demandado hubiera sido citado para comparecer [a no ser que la resolución que contenga la medida le sea notificada antes de su ejecución; art. 2, letra a) y considerando 33].

15. Aunque el principio inaudita parte ha merecido alguna crítica, estimamos adecuado su establecimiento si tenemos en cuenta que el riesgo que trata de conminar la orden es la facilidad extrema con que el deudor puede disponer de los fondos, en pocos segundos, gracias a las prestaciones de la banca electrónica.

16. El principio inaudita parte es independiente de la situación en que se encuentre el acreedor, según esté provisto de resolución judicial, transacción judicial o documento público con fuerza ejecutiva; de ahí que el procedimiento solo sea compatible con el derecho del deudor a la tutela judicial si se prevén mecanismos adecuados para su defensa procesal, así como para hacer frente a los daños y perjuicios que la retención pudiera depararle si, finalmente, la pretensión de pago es desestimada. Los mecanismos que equilibran el tándem "eficacia de la orden-garantías del deudor»son: i) la posible exigencia al acreedor de una caución previa a la adopción de la orden, aunque el Reglamento huye del automatismo en su exigencia (art. 12); ii) el régimen europeo de responsabilidad del acreedor, aplicable a los Estados miembros sin perjuicio del aditamento que puedan establecer en sus respectivos ordenamientos (art. 13), y iii) los medios de impugnación que el deudor puede utilizar contra la orden o contra su ejecución («recursos» ex arts. 33 y 34).

17. En garantía de que el deudor pueda articular una defensa real, el Reglamento exige que tras la retención se le notifiquen «sin demora» la orden y los documentos presentados por el acreedor al órgano jurisdiccional del Estado miembro de origen (art. 28.1).

18. Otro factor destacable es que junto a la pretensión de tutela cautelar el acreedor puede instar al órgano jurisdiccional que requiera a la «autoridad de información» del Estado miembro de ejecución para que le proporcione información sobre las cuentas que el deudor mantiene en un banco de su territorio (art. 14). Esta petición es instrumental respecto de la orden, pero si su resultado fuera infructuoso conduce a su desestimación, dado que la OERC es una medida real que se adopta sobre cuentas determinadas del deudor, no sobre su persona ni sobre la generalidad de sus bienes patrimoniales.

19. Como regla general, la petición de información solo procede si el acreedor ha obtenido una resolución judicial, una transacción judicial o un documento público con fuerza ejecutiva que obligue al deudor al pago de la deuda (art. 14.1). Si la reclamación es objeto de un proceso jurisdiccional 
-ya pendiente o por incoar-, la petición de información sobre las cuentas es inviable; y ello, no solo por la eventualidad de que la pretensión del actor pueda ser desestimada sino por la falta de proporcionalidad que entrañaría que se libraran datos personales del deudor sin la mínima cobertura de un pronunciamiento condenatorio. La solución por la que opta el Reglamento nos parece razonable, pues una cosa es que se autorice la petición de información si concurren determinados requisitos y otra diferente que el órgano jurisdiccional y la "autoridad de información» integren, de forma generalizada, la carga de la localización de las cuentas que corresponde al acreedor.

20. Problemática ha sido, en el conjunto de los Estados miembros, la designación de la «autoridad de información»; y dispar el resultado que los Estados han comunicado a la Comisión ${ }^{8}$. Algunos Estados como Alemania, España o Irlanda han designado al Ministerio de Justicia; otros se han decantado por una designación «funcional», como Francia a favor de los huissiers de justice o Portugal a favor de la Ordem dos Solicitadores e Agentes de Execução (OSAE); algún otro Estado como Luxemburgo ha designado al organismo de supervisión financiera (Commission de Surveillance du Secteur Financier). A nuestro parecer, la designación más idónea es la que, como en el caso de Italia, recae sobre la autoridad judicial, aunque ello comporte la dispersión territorial de los órganos de información. En este sentido, la designación efectuada por España obedece a la dificultad — sin reforma legislativa- de atribuir dicha función a un órgano jurisdiccional único, así como a que dicha tarea excede las propias de los jueces decanos ${ }^{9}$.

\section{EJECUCIÓN Y CUMPLIMENTACIÓN DE LA ORDEN: SUPRESIÓN DEL EXEQUÁTUR Y PRÁCTICA DE LA RETENCIÓN}

21. La ejecución de la orden es la materia en que con mayor relieve afloran las diferencias que separan los ordenamientos de los Estados miembros. Ello determina que su regulación, más que compleja sea casuística y esté plagada de incisos, salvedades, remisiones al Derecho nacional y fórmulas impersonales.

22. El Reglamento prescinde del exequátur, e impone a los Estados miembros el reconocimiento y la ejecución de la orden dictada en uno de ellos (art. 22). El reconocimiento es universal, con independencia de que el acreedor estuviera provisto de una resolución judicial, una transacción judicial o un documento público con fuerza ejecutiva; lo cual es lógico, dado que el reconocimiento tiene por objeto una medida cautelar y no conlleva el reconocimiento de la resolución, la transacción o el documento público. Cuestión diferente es que la desestimación en el Estado miembro de ejecución, de la

\footnotetext{
8 Disponible en el Portal Europeo de e-Justicia: https://e-justice.europa.eu/content_european_account_preservation_order-379-es.do?init=true (consultada el 2 de junio de 2017).

${ }^{9}$ La designación ha recaído en la Subdirección General de Cooperación Jurídica Internacional, que recabará la información del Punto Neutro Judicial (CGPJ).
} 
ejecución de la resolución o la transacción judicial o del documento público con fuerza ejecutiva cuya ejecución trataba de garantizar la orden, aboque a que esta se deje sin efecto, al ser incompatibles, en un mismo Estado miembro, la desestimación del título principal y el mantenimiento de la medida cautelar [art. 34.1, letra b), ii)].

23. El Reglamento se nutre de las «estructuras» de ejecución de los Estados miembros (considerando 23) y dispone que el banco cumplimente la orden de una de estas dos formas: a) velando por que dicho importe no se transfiera ni retire de la cuenta o las cuentas indicadas en la orden o identificadas de acuerdo con el apartado 4, o b) si así lo dispone el Derecho nacional, transfiriendo dicho importe a una cuenta destinada a fines de retención (art. 24.2). Esta segunda modalidad es la aplicable en Derecho español, mediante transferencia a la Cuenta de Depósitos y Consignaciones del órgano jurisdiccional correspondiente.

24. El Reglamento contiene normas que disciplinan la actuación del banco frente a posibles incidencias, entre las que destaca aquella que autoriza que la retención se supedite «al pago de operaciones que ya estén pendientes en el momento en que el banco reciba la orden» (art. 24.2). A nuestro parecer, la norma adolece de falta de concreción sobre qué debe entenderse por "operaciones pendientes», lo que unido a la posibilidad de efectuar el pago hasta que el banco expida la "declaración sobre la retención de fondos» (en los tres días hábiles siguientes a la retención) pudiera cobijar alguna práctica irregular; señaladamente, cuando las operaciones pendientes sean cargos en cuenta al deudor por créditos propios del banco requerido.

\section{RETENCIÓN DE CUENTAS CONJUNTAS Y NOMINALES: REENVÍO AL DERECHO DEL ESTADO MIEMBRO DE EJECUCIÓN}

25. El Reglamento autoriza la retención de los fondos depositados por el deudor en cuentas en régimen de cotitularidad y en cuentas titularidad de un tercero («nominales») en la medida en que estén sujetos a retención con arreglo al Derecho del Estado miembro de ejecución. El reenvío se extiende a los fondos depositados en cuentas titularidad del deudor por cuenta de un tercero (art. 30). La razón del reenvío es el diverso tratamiento procesal que estas cuentas reciben en los Estados miembros y aboca a una aplicación dispar de la orden en el conjunto de la Unión.

26. Respecto al tratamiento procesal de las cuentas de cotitulares en Derecho español, quizás lo más destacable sea la ausencia de una norma sobre el embargo, en el bien entendido sentido que en el proceso civil no son aplicables las normas tributarias (art. 171.2 de la Ley 58/2003, de 17 de diciembre, General Tributaria) ${ }^{10}$. De ahí los pronunciamientos encontrados de los

10 BOE núm. 302, de 18 de diciembre de 2003. 
tribunales, dado que el Tribunal Supremo reitera que la cotitularidad de la cuenta, por si sola, no supone el condominio de los fondos y que la viabilidad del embargo no se cuestiona (art. 593.1 LEC). En este contexto, merece ser destacado el impulso que ha supuesto el Reglamento para la elaboración en el seno de la Comisión General de Codificación de una propuesta de reforma de la LEC que afronte el embargo de cuentas de cotitulares.

27. Por su parte, la retención de cuentas nominales es «materia sensible» por la implicación de los mercados financieros. Quizás por ello, varios Estados las han omitido en sus comunicaciones [art. 50.1, letra $g$ )].

\section{VALORACIÓN FINAL}

28. La OERC constituye una apuesta decidida de la Unión Europea a favor de la tutela cautelar del crédito en asuntos transfronterizos. Ello no significa que el régimen jurídico de la orden sea plenamente satisfactorio. La indeterminación presente en algunos preceptos y las numerosas remisiones al Derecho de los Estados sobre cuestiones muy relevantes auguran una aplicación dispar en el conjunto de la Unión. Como toda normativa extensa y compleja, el Reglamento tiene luces y sombras, aunque a nuestro parecer, la balanza se inclina a favor de las primeras.

29. Más allá de la valoración que suscite esta reglamentación, nos parece decisiva su incidencia como motor de una futura reforma de la LEC que implemente la regulación del embargo para supuestos tan cotidianos como las cuentas de cotitulares o el abono en cuenta de sueldos y pensiones.

Palabra clave: orden europea de retención de cuentas, embargo de cuentas bancarias, tutela cautelar del crédito, asuntos transfronterizos.

Keywords: European account preservation order, bank accounts attachment, provisional measures for the enforcement of claims, cross-border cases. 